\title{
Managing Patient Trust in Managed Care
}

\author{
HUW T.O. DAVIES \\ and THOMAS G. RUNDALL \\ University of St. Andrews; University of California, Berkeley
}

RECENT SURGE OF INTEREST IN TRUST
relationships in the provision of medical care has generated a
large body of literature describing and documenting the importance of patient-physician trust to effective medical care (Davies 1999; Mechanic 1996; 1998; Mechanic and Schlesinger 1996; Shortell, Waters, Clarke, et al. 1998; Waitzkin and Fishman 1997). Recent scholarship on patient-physician trust has raised the concern that many characteristics that distinguish managed care may also contribute to erosion of patients' trust in their physicians (Mechanic 1996; Mechanic and Schlesinger 1996; Mechanic 1998). While we largely agree with these analyses, we argue that patient-physician trust should not be viewed simplistically - that more is good and less is always bad. In the context of the larger literature on trust relationships, and of increasing awareness of errors by physicians in making treatment decisions (Kohn, Corrigan, and Donaldson 1999), it seems reasonable to ask: what level of trust in physicians is optimal in any given set of circumstances? We explore this issue in the context of managed care as it has developed in the United States.

In this article, we first analyze trust in the patient-physician relationship by exploring its benefits and pitfalls and commenting on the likely impact of many key features of managed care on this trust. We then

The Milbank Quarterly, Vol. 78, No. 4, 2000

(c) 2000 Milbank Memorial Fund. Published by Blackwell Publishers, 350 Main Street, Malden, MA 02148, USA, and 108 Cowley Road, Oxford OX4 1JF, UK. 
argue that patient-physician trust is linked to the level of interdependence between patient and physician. Here we introduce the concept of total patient benefit, which is a function of the health outcome from a physician encounter and the costs associated with the patient's efforts to monitor and assess the quality of care provided. Finally, we theorize about the implications for total patient benefit of good matches between the levels of trust and interdependency — which we call optimal trust — and we consider the consequences of mismatches between these two constructs. We propose three hypotheses regarding patient-physician interdependency, trust, and total patient benefit in order to stimulate empirical research on these issues. Our analysis suggests that patients may overor underinvest in trust, depending on the level of interdependence, thus reducing their total benefit from the relationship. In concluding, we suggest some implications of focusing on optimal patient-physician trust for health policymakers and managers.

\section{Background: The Growth of Managed Care}

Since the late 1980s, a new health care environment has emerged in many parts of the United States. Previously, indemnity insurance and feefor-service reimbursement prevailed. Independent physicians, hospitals, and other caregivers provided medical services and billed the charges to the patient's insurance company, the government, or in some cases the patient. As long as the fee was "usual, customary, and reasonable," the patient, insurance company, or government paid-with little regard to the appropriateness of services delivered. Physicians had few, if any, constraints on their authority to order tests, perform procedures, make referrals, and prescribe medications. In general, patients perceived that such unbridled authority for physicians to expend resources on their behalf aligned the physicians' interests (autonomy and personal financial gain) with their own (access to all interventions regardless of cost).

In the new health care environment, private employers and the federal and state governments have changed from passive payers to aggressive purchasers of health care. As such, they demand more accountability from health plans with respect to where their insured employees are cared for, what types of services are provided, and how much they will pay. In turn, health insurance companies have devised a variety of managed care plans (e.g., group and network model health maintenance organizations) that 
shift some of the risk of controlling health care costs to the care providers. When at financial risk for the cost of the services they provide, physicians and hospitals have a strong incentive to manage carefully the entire continuum of care for their enrolled patient population (Shi and Singh 1998; Rundall 1999). Hence the origins of the term "managed care."

\section{Managed Care and Patient Trust}

Recent survey research in the United States has documented the erosion of patients' trust in their health plans, and has linked this erosion to managed care. For example, in a 1997 survey, 52 percent of the U.S. population agreed with the statement: "Government needs to protect consumers from being treated unfairly and not getting the care they should from managed care plans" (Blendon, Brodie, Benson, et al. 1998). Moreover, 51 percent of Americans agreed with the statement: "During the past few years, HMOs and other managed care plans have decreased the quality of care for people who are sick" (Blendon et al. 1998). Indeed, in 1997, only 30 percent of Americans in managed care plans agreed that they trust their health insurance plan to "do the right thing for your care just about always," whereas 55 percent of those enrolled in a traditional indemnity insurance plan agreed with that statement (Blendon et al. 1998).

A potentially significant finding is that the traditionally high level of trust in the patient-physician relationship has also been eroded (Kao, Green, Zaslavsky, et al. 1998). Some researchers have concluded that managed care plans have in some instances forced physicians to become "double agents," dividing their allegiance between their patients and their physician organization or managed care plan (Angell 1993; Waitzkin and Fishman 1997; Shortell et al. 1998). Public concerns have been exacerbated further by regular and widespread reporting of manifest professional failings (Chassin and Galvin 1998; Davies and Shields 1999), together with highly critical populist analyses of managed care trends (Anders 1996).

\section{The Nature and Role of Trust}

We now explore the nature of trust, as distinguished from dependency and faith. Trust arises between two parties under several conditions. 
First, there must be some interdependency between the two parties; that is, the actions of one must have import and impact on the other. Second, there must be some maneuverability or choices to be made by either party. Third, attached to these choices must be some uncertainty or risk. Given such a situation, one or both parties can choose to place some trust in the other. That is, they can choose to rely on the other party to act in their best interest-independent of verification or other forms of reassurance. The act of choice in placing trust is central: trust without choice is dependency (when one party is bound to the other and at risk from the other without choice). Furthermore, one's trust must be based on experience with or knowledge of the other party's behavior in similar situations that provides a rational basis for believing that the other party has the competence and willingness to act in one's best interest. Trust without any such basis in experience or knowledge is more properly regarded as faith or hope.

Trust, then, is manifested by a number of expectations by one party about the capabilities and behavior of the other: expectations of competence, predictability, fairness, and a lack of opportunism (Gambetta 1988; Zaheer, McEvily, and Perrone 1998; Davies and Mannion 1999a; 1999b). Trust has been much studied in the social science literature, especially in the context of intra- and interorganizational relationships. There it has been suggested that trust can lower transaction costs, improve performance, and facilitate cooperation (Kramer and Tyler 1996; Lane and Bachmann 1998; Davies and Mannion 1999a; Mannion and Davies 2000). Thus, trust is a lubricant that enables relationships to function smoothly, a glue that binds people in mutually rewarding relationships, and a stimulant that allows greater creativity, innovation, and performance.

Creating and maintaining trust is no easy matter, requiring repeated interactions and consistent experiences. There is also an important asymmetry between trust and distrust: trust may take a long time to build but it is fragile and easily damaged or even destroyed. Once it has been lost, trust may be difficult or even impossible to regain. It is vulnerable even to small breaks of faith, or suspicions of such. Hence aberrant events, anecdote, and media reporting all influence the extent of trust disproportionately (Davies 1999). Furthermore, the extent of trust in a given setting is bound to be influenced by wider contextual variables and social trends (Mechanic 1996; Wicks, Berman, and Jones 1999). 


\section{Trust in Health Care}

Trust lies at the heart of the physician-patient relationship. Individuals consult their physician trusting that the physician will act and advise with the patient's interests uppermost. Indeed, this placing of the interests of individual clients above all other interests is a hallmark of professional practice. As in other professional relationships, some measure of trust is largely unavoidable. The asymmetries of knowledge and expertise between physician and patient mean that it is the rare patient who is able to question, cross-check, and verify all aspects of the physician's conduct and counsel. Although some patients are very well informed, some indeed whose knowledge of their medical problems surpasses that of the physician, these asymmetries predominate. Another important basis for unavoidable trust in the patient-physician relationship is the sense of vulnerability that often accompanies a patient's illness and injury. Thus, to some extent, patients must place their trust in their physicians (and oftentimes in other health care workers also). How much trust patients should invest in their relationship with a physician is, as we argue below, influenced by the organizational, financial, and legal situation within which their health care is delivered.

In exploring the nature of trust in health care, David Mechanic identified five distinct expectations that patients can legitimately hold about their physicians (Mechanic 1996). These are the expectations of: agency (that the physician will act in the best interests of the patient); competence (that the physician possesses the skills and knowledge necessary for effective care); control (that the physician can command the resources necessary); confidentiality (that personal information will be shared only as required for the patient's care); and disclosure (that the physician will not withhold from the patient any important and relevant information) (Mechanic 1996; Mechanic and Schlesinger 1996; Mechanic 1998). These conceptual distinctions are useful for assessing the effect of managed care cost-control activities on patient-physician trust. However, empirical research indicates that these indicators of trust are highly correlated and probably represent dimensions of a single factor (Kao, Green, Zaslavsky, et al. 1998; Thom, Ribisl, Stewart, et al. 1999). Hence, a patient's overall trust in physicians may be viewed on a continuum from low to high.

In the context of physician-patient relationships, certain payoffs may be expected from high-trust relationships, but so far little substantial empirical work has been done to confirm this. The potential gains from 
high levels of patient trust in physicians include: a reduced burden on the patient (less need to check); reduced shopping around for health care (fewer second opinions; trust in physician advocacy); better patient loyalty; fuller patient disclosure; improved two-way communication; better treatment compliance; improved patient satisfaction; improved outcomes (arising, for example, from better compliance with treatment and an increase in the placebo effect); greater patient reassurance and reduced anxiety; and potentially less litigation. Finally, without trust there can be little caring, and caring is central to health care. This long list of benefits does need further empirical support but it clearly suggests that high levels of patient trust in physicians may be a useful but largely unseen component of effective, efficient, and appropriate health care.

Of course, patient trust in physicians is not without pitfalls. Trust can be misplaced and trust can be abused. With trust comes scope for opportunism, paternalism, and the potential overexposure to risk. When trust is misplaced, some of the expectations outlined above may fall short, with deleterious results. The rich evidence documenting the failings in quality of health care and variations in practice suggests that a patient's expectations of agency, competence, and physician control are clearly not always warranted (Anderson 1990; Chassin and Galvin 1998; Schuster, McGlynn, and Brook 1998; Kohn, Corrigan, and Donaldson 1999). Further, an overreliance on trust may lead a patient to neglect other, more appropriate ways of dealing with uncertainty and risk (e.g., seeking further information, obtaining a second opinion, or searching for independent verification).

\section{Some Implications of Managed Care for Patient-Physician Trust}

Managed care provides a radically new context for physician-patient interaction and is rapidly becoming the dominant mode of health care delivery in the United States. Managed care has brought to the fore a range of tactics (e.g., selective contracting, risk sharing, use of hospitalists, formularies, preauthorization requirements, practice guidelines, and utilization review) that have profound implications for patient-physician trust. These features of managed care may change what patients expect of their physicians, and so interfere with trust. 
First, some provisions (e.g., limiting choice through selective contracting, use of hospitalists, or risk sharing) introduce the fear that physicians have to consider the priorities and expectations of parties other than the patient (i.e., those of the payer) when making diagnostic and treatment decisions. Thus, the expectation of agency is compromised. No longer are the patients' interests paramount; now they must be balanced with possibly competing interests.

Second, several cost-control aspects of managed care (selective contracting, pharmacy benefits management, and preauthorization) undermine patients' expectations that their physicians have control over the necessary resources and access to the necessary expertise to ensure firstclass treatment. This area of managed care has drawn the most criticism from patients, patient advocacy groups, legislators, and physicians themselves. As a result, trust in managed care remains low (Anders 1996; Blendon et al. 1998).

Third, some managed care provisions (e.g., guidelines, preauthorization, and utilization review) may undermine patients' expectations of competence in their physicians. Such features of managed care send a signal to patients that doctors are incapable of making competent decisions about treatment strategies and have to be guided or even coerced into appropriate practice.

Finally, the interposition of people other than direct caregivers into the patient-carer relationship (e.g., those involved in preauthorization and patient care coordinators) raises legitimate fears about the extent of confidentiality and the prospects of full disclosure.

Of course, some provisions of managed care (e.g., formularies, utilization review) simultaneously undermine several of the key expectations necessary for a trusting relationship, such as agency, control, and competence.

It is important to note that the impact of managed care on patients' trust in physicians is not always negative. Some of the arrangements under managed care may work to promote specific aspects of trust. For example, the introduction of primary care physicians, who serve a gatekeeping function for the health plan, also offers patients greater continuity of care and the chance to build trusting relationships with their physicians based on personal experience. Similarly, limiting patients to specific providers may also build trust through repeated contacts. If these selected providers are also seen as high-quality with substantial reputations, this too may enhance patient confidence. 
Furthermore, some measures used (e.g., physician profiling, the use of care management guidelines and protocols) may have inconsistent effects on trust. Certain people may find them reassuring (buttressing their trust) while others may find the same features confidence-shaking. In many cases, the impact of managed care provisions can be expected to vary among individuals and contexts.

In sum, managed care greatly complicates the patient-physician relationship, setting up competing and conflicting pressures on the physician (Angell 1993; Waitzkin and Fishman 1997; Shortell et al. 1998). Patients are not oblivious to these pressures and such knowledge affects their level of trust (Blendon et al. 1998; Kao et al. 1998). Thus patientphysician trust exists on a continuum and is affected by the organizational arrangements for health care. Dangers and costs are associated with both an absence of trust and an over-reliance on trust. This suggests that there may be levels of trust that are optimal for a given purpose and, crucially, a given set of circumstances (Wicks, Berman, and Jones 1999).

\section{Patient-Physician Interdependence, Total Patient Benefit, and Optimal Trust}

To discuss optimal trust in health care, we first expand on the notion of interdependency in the patient-physician relationship and then introduce the concept of total patient benefit. The degree of interdependence in a relationship is a function of the degree to which both parties are dependent on each other to achieve their desired outcomes (Wicks, Berman, and Jones 1999). Dependence is the extent to which outcomes are controlled by, or are contingent upon, the action of another party. Clearly, patients depend on the specialized knowledge, treatment expertise, hospital admitting privileges, legal authority to prescribe drugs, and other abilities unique to physicians in order to achieve a desired outcome, typically the amelioration of disease or injury. The level of this dependence may vary. For example, when health care is routine, technologically simple, lowcost, and not life-threatening (e.g., immunizations, simple analgesics for minor bumps and sprains, or antibiotics for minor infections), then dependence may be low. In contrast, when the care sought is unusual, technologically complex, high-cost, or potentially life-threatening (e.g., major surgery, assisted conception, or cancer treatment), then patient dependence on physicians is much higher. 
Less frequently discussed is the extent to which physicians are dependent on their patients. This dependency is greatest when the physician receives fee-for-service (FFS) indemnity reimbursements, independent physicians work in solo practices, and patients are completely free to choose from a reasonably large pool of physicians. Under such circumstances, physicians are dependent on patients for their immediate and future income. Freidson referred to such situations as potentially placing the physician under "lay control" (Freidson 1970). To be chosen by a patient, the physician must be perceived to offer the services that patients feel they need "and to be chosen again and survive, he must be prepared to provide services that honor the client's prejudices sufficiently to make him feel that what he thinks bothers him is being properly treated" (Freidson 1970, p. 107).

At the other extreme, when the patient's choice of physician is restricted, alternative choices are limited, and the physician is salaried, then the physician has virtually no dependency on the patient. There is, of course, a dependency on patients in the general sense that there must be a sufficient number of patients requiring care to justify the physician's salaried position. However, the dependency of a particular physician on a particular patient under these circumstances is quite low. Other organizational and financial arrangements, such as restricted choice with FFS physician reimbursement and restricted choice with capitated physician payment, fall between these two extremes in terms of the dependency of the physician on the patient.

Next, we turn to total patient benefit. In significant interpersonal exchanges of all sorts, a low level of trust typically leads one party to seek data on the other party's previous performance and to monitor and assess the other party's current performance with respect to the transaction. Thus, patients with relatively low levels of trust in a physician often incur time and monetary costs to assure themselves that the physician is acting in their best interests. In every episode of illness, then, the total patient benefit of being treated by a given physician is determined by the extent to which the patient's desired health outcome was achieved and the financial, agency, and transaction costs required to insure that the physician was acting in the patient's best interest. In calculating total patient benefit, it is reasonable to assume that health outcome will be more heavily weighted than the patient's costs. However, we argue that typically the costs of checking are not insignificant and, in many instances, will substantially affect the patient's total benefit from 
a physician's care for an episode of illness, particularly in the case of non-life-threatening injury or illness.

From these discussions, we argue that the optimal trust level for maximizing total patient benefit is a function of the level of interdependence between patient and physician. When trust and interdependence are matched (both high or both low), then the trust levels may be optimal for maximizing total patient benefit (Venkatraman 1989). For instance, a high level of patient trust is well matched where the physician is a solo practitioner compensated by third-party fee-for-service reimbursement and the patient is completely free to choose any physician from a wide range of alternatives. The high level of interdependence is matched with a high level of trust. The patient's freedom of choice will motivate the physician to allocate resources and exercise judgment in ways that convince the patient that the physician is doing everything possible to achieve the patient's desired outcome. High trust relationships of this sort reduce the patient's need to engage in costly searching and monitoring behaviors. The patient also benefits by the willingness of physicians to extend themselves readily for the patient's benefit without explicit incentives.

Conversely, low interdependency can be well matched with lower levels of trust. In circumstances where the physician is not dependent on the patient, the patient is likely to have a low level of trust in the physician (relative to that found in high-interdependency, high-trust situations). Nonetheless, this may still be an optimal level of trust since the physician could be less motivated to act in ways to maximize the chances of achieving the patient's desired outcome, and the physician's internalized sense of professionalism may be challenged by other organizational and financial considerations. Such low-trust, low-dependency relationships can be costly: when they result from the way managed care agreements are structured, third parties (e.g., regulatory agencies, medical group physician credentialing departments) are often created to monitor physician performance. Moreover, patients themselves may spend more time and resources doing such monitoring and checking to the extent feasible, in an attempt to increase the likelihood that they will receive the appropriate treatment in an efficient way from the appropriate provider.

Suboptimal trust occurs when the level of trust is poorly matched to a given level of interdependence. Without roughly similar levels of dependence (patient on physician, physician on patient), mutual trust can readily become unstable. One version of mismatching occurs when 
a patient's trust is insufficient to sustain the level of interdependence between the patient and the physician. Another version occurs when a patient invests more in creating and maintaining levels of trust than is indicated for the degree of interdependence with a given physician. Selecting a trust level that is too high creates a suboptimal hedge against opportunism, and may need to be counterbalanced by institutional oversight.

Building on these ideas, we propose three hypotheses regarding patientphysician trust:

1. The greater the degree of interdependence between patient and physician, the higher will be the average level of trust patients have in their physician.

2. In patient-physician relationships that are highly interdependent, patients with high levels of trust in their physician will experience greater total patient benefit than patients with low levels of trust.

3. In patient-physician relationships that have a low degree of interdependence, patients with a relatively low level of trust in their physician will experience greater total patient benefit than patients with high levels of trust.

There is an important caveat regarding these hypotheses: Mechanic's five dimensions of trust (agency, competence, control, confidentiality, and disclosure) are different in kind and are not of equal importance. In particular, physician competence is an intrinsic attribute of the physician whereas agency, control, confidentiality, and disclosure are manifest to different degrees by the physician's actions. Thus, an assessment of competence is crucial to the selection of a physician, whereas our focus has been the management of the subsequent patient-physician relationship. Hence, nothing in this discussion of optimal trust relieves the patient (or the system) of the burden of assessing the physician's basic abilities before entering into a therapeutic relationship.

Given the embedded nature of patient-physician trust and the complexity of many organizational and financial arrangements under managed care, empirically testing these hypotheses will be a substantial challenge. However, we are encouraged by the findings from recent research on the relationship between the method of physician payment and patient trust (Kao et al. 1998). Survey data from 2,086 adult managed care and indemnity patients revealed that more fee-for-service indemnity 
patients (94 percent) completely or mostly trust their physicians to "put their health and well-being above keeping down the health plan's costs" than fee-for-service managed care patients ( 85 percent), capitated patients ( 83 percent), or patients with salaried physicians ( 77 percent). In multivariate analyses that adjusted for potentially confounding factors, FFS indemnity patients scored higher on the investigators' 10-item trust scale than patients with salaried physicians, capitated plans, or FFS managed care plans. Introducing a variable measuring patients' reports about physician behaviors reduced the effect of the method of payment on patient trust but it remained statistically significant. Although this study did not strictly test our ideas about interdependence and optimal trust, the findings are consistent with our first hypothesis and lend credence to the arguments we have presented.

\section{Implications for Physicians and Health Care Managers}

We believe that the conceptual framework presented here is an important contribution. Too much health policy research takes place in a theoretical vacuum. Yet the theoretical framework that underpins empirical work can profoundly influence which problems are identified, how they are cast, and how empirical data are gathered to elucidate them (Kuhn 1962). Trust underpins almost all nontrivial human interactions, notwithstanding increased bureaucratic control, increased complexity of contractual arrangements, and escalating litigation. Very often, however, trust remains in the background (Davies 1999), while the more tangible aspects of relationships receive the most attention. Bringing issues of trust to the fore in theoretical encapsulations, empirical analyses, and operational responses may therefore prove to be useful.

We have highlighted how the professional relationship between physician and patient, at the heart of health care for so long, is now changing as the physician's dependency on patients is being reduced by new organizational, financial, and practice arrangements-what is commonly called managed care. We have argued that the resulting erosion of trust is not inherently bad. Rather, we have postulated that, from the patient's perspective, there is an optimal level of trust in a physician that will vary depending on the circumstances. In situations where physician dependency on patients is low, patients may increase the total benefit derived 
from their relationship with a physician by trusting less and checking more. Whether this is necessary depends on the extent to which the physicians' intrinsic professional motivations are constrained, compromised, or even eroded by the institutional context within which they work.

If future research supports our arguments about patient-physician trust, interdependency, and total patient benefit, several strategic thrusts by physicians and health managers are indicated. First, for physicians in "heavy" managed care organizations, it is unrealistic and potentially damaging to the therapeutic relationship to insist that patients trust them unquestioningly. Physicians in heavy managed care settings would be wiser to accept that it is not only common but rational for patients to have less than a maximum amount of trust in their physician and therefore it is reasonable that the patient should seek further information to buttress this lack of trust.

Second, to establish and sustain loyalty in their patients, physicians and managers need to collaborate closely to build quality improvement and accountability systems that are accessible to patients and that satisfy their need to check rather than to trust completely. Managed care organizations are already doing this, to some extext (Mechanic 1996; Gray 1997; Goldberg 1998; Mechanic 1998), as are private sector organizations such as the Pacific Business Group on Health. However, these efforts thus far have focused on assuaging the concerns of payers, particularly employers, rather than the concerns of patients. Mechanic and Rosenthal (1999) documented some of the efforts directed at patients and showed that only a minority of HMOs was involved in many of them. Our analysis suggests that quality improvement and performance accountability systems could complement patient trust in physicians in a managed care setting and thereby improve their relationship.

Third, some physicians and health plans are developing organizational and financial arrangements that increase the physician's dependency on the patient. Offering patients a greater choice of physician and unlimited opportunities to change their primary care provider would increase patient-physician interdependency. Perhaps more substantial would be the development of physician compensation systems in which a substantial portion of total compensation is based on fee-for-service payment and on an individual physician's scores on routine patient satisfaction surveys.

Some readers will be astonished by our arguments about optimal patient-physician trust. The belief that patients must have complete trust 
in physicians for the therapeutic relationship to be effective is widespread and deeply held by many people. We do not reject the possibility that patients' trust in their physician has some sort of therapeutic benefit, or enables some therapies to be beneficial when they otherwise might not be. In this sense, trust may be an unqualified good. But that is not the issue we address here. Instead, we ask why is patient-physician trust eroding in managed care settings, and what are the implications of that erosion? We suggest that the implications may not always be bad for the patient. But, more important, we have attempted to transform what is often an emotional debate into a set of researchable questions. The concepts we have introduced-patient-physician interdependency, optimal patient trust, and total patient benefit-provide a framework within which to answer these questions.

\section{References}

Anders, G. 1996. Health against Wealth: HMOs and the Breakdown of Medical Trust. Boston and New York: Houghton Mifflin.

Anderson, T.F. 1990. The Challenges of Medical Practice Variations. Basingstoke, Eng.: Macmillan.

Angell, M. 1993. The Doctor as Double Agent. Kennedy Institute of Ethics Journal 3:279-86.

Blendon, R.J., M. Brodie, J.M. Benson, et al. 1998. Understanding the Managed Care Backlash. Health Affairs 17:80-94.

Chassin, M.R., and R.W. Galvin. 1998. The Urgent Need to Improve Health Care Quality. Institute of Medicine National Roundtable on Health Care Quality. Journal of the American Medical Association 280(11):1000-5.

Davies, H.T.O. 1999. Falling public trust in health services: Implications for accountability. Journal of Health Services Research and Policy 4(4):193-4.

Davies, H.T.O., and R. Mannion. 1999a. Clinical Governance: Striking a Balance between Checking and Trusting. Reforming Markets in Health Care: An Economic Perspective, ed. P.C. Smith. Milton Keynes, Eng.: Open University Press.

Davies, H.T.O., and R. Mannion. 1999b. The Rise of Oversight and the Decline of Mutuality. Public Money \& Management 19(2):55-9.

Davies, H.T.O., and A. Shields. 1999. Public Trust and Accountability for Clinical Performance: Lessons from the Media Reporting of the Bristol Enquiry. Journal of Evaluation in Clinical Practice 5:335-42. 
Freidson, E. 1970. Profession of Medicine: A Study of the Sociology of Applied Knowledge. New York: Dodd, Mead.

Gambetta, D., Ed. 1988. Trust: Making and Breaking Co-operative Relations. Oxford: Blackwell.

Goldberg, R.K. 1998. Regaining Public Trust. Health Affairs 17(6): 138-41.

Gray, B.H. 1997. Trust and Trustworthy Care in the Managed Care Era. Health Affairs 16(1):34-46.

Kao, A.C., D.C. Green, A.M. Zaslavsky, J.P. Koplan, and P.D. Cleary. 1998. The Relationship between Method of Physician Payment and Patient Trust. Journal of the American Medical Association 280: 1708-14.

Kohn, L.T., J.M. Corrigan, and M. Donaldson. 1999. To Err Is Human: Building a Safer Health System. Washington, D.C.: Institute of Medicine.

Kramer, R.M., and T.R. Tyler, Eds. 1996. Trust in Organizations: Frontiers of Theory and Research. Thousand Oaks, Calif.: Sage.

Kuhn, T.S. 1962. The Structure of Scientific Revolutions. Chicago: University of Chicago Press.

Lane, C., and R. Bachmann, Eds. 1998. Trust within and between Organizations. Oxford: Oxford University Press.

Mannion, R., and H.T.O. Davies. 2000. Trust (Economics). Reader's Guide to the Social Sciences. Chicago: Fitzroy Dearborn.

Mechanic, D. 1996. Changing Medical Organization and the Erosion of Trust. Milbank Quarterly 74:171-89.

Mechanic, D. 1998. The Functions and Llimitations of Trust in the Provision of Medical Care. Journal of Health Politics, Policy and Law 23(4):661-86.

Mechanic, D., and M. Rosenthal. 1999. Responses of HMO Medical Directors to Trust Building in Managed Care. Milbank Quarterly 77:283-303.

Mechanic, D., and M. Schlesinger. 1996. The Impact of Managed Care on Patients' Trust in Medical Care and Their Physicians. Journal of the American Medical Association 275:1693-7.

Rundall, T.G. 1999. Managed Care and the Transformation of the American Health Care System. Keio Business Forum 17(2):3-18.

Schuster, M.A., E.A. McGlynn, and R.H. Brook. 1998. How Good Is the Quality of Health Care in the United States? Milbank Quarterly 76:517-63.

Shi, L., and D.A. Singh. 1998. Delivering Health Care in America. Gaithersburg, Md.: Aspen.

Shortell, S.M., T.M. Waters, K.W.B. Clarke, and P.P. Budetti. 1998. 
Physicians as Double Agents: Maintaining Trust in an Era of Multiple Accountabilities. Journal of the American Medical Association 280:1102-8.

Thom, D.H., K.M. Ribisl, A.L. Stewart, D.A. Luke, and the Stanford Trust Study Physicians. 1999. Further Validation and Reliability Testing of the Trust in Physicians Scale. Medical Care 37:1-7.

Venkatraman, N. 1989. The Concept of Fit in Strategy Research: Toward Verbal and Statistical Correspondence. Academy of Management Review 14:423-44.

Waitzkin, H., and J. Fishman. 1997. Inside the System: The PatientPhysician Relationship in the Era of Managed Care. Competitive Managed Care: The Emerging Health Care System, ed. J.D. Wilkerson, K.J. Devers, and R.S. Given, 136-61. San Francisco: Jossey-Bass.

Wicks, A.C., S.L. Berman, and T.M. Jones. 1999. The Structure of Optimal Trust: Moral and Strategic Implications. Academy of Management Review 24(1):99-116.

Zaheer, A., B. McEvily, and V. Perrone. 1998. Does Trust Matter? Exploring the Effects of Interorganizational and Interpersonal Trust on Performance. Organization Science 9(2):141-59.

Acknowledgments: One author (Huw Davies) held the position of Harkness Fellow in Health Care Policy at the University of California, San Francisco (UCSF), during the preparation of this paper. Thus this work was supported by The Commonwealth Fund, a New York City-based private independent foundation. However, the views presented here are those of the authors and not necessarily those of The Commonwealth Fund, its directors, officers, or staff. Huw Davies is sincerely grateful to the Fund and to the Institute for Health Policy Studies at UCSF for the opportunities afforded to him by the Harkness Fellowship.

Address correspondence to: H.T.O. Davies, Department of Management, University of St Andrews, St Katharine's West, The Scores, St Andrews Fife KY16 9AL, United Kingdom (e-mail: hd@st-and.ac.uk). 